\title{
Escenografía de la piel: sobre el cuerpo-escena como espacio ocioso (J-L. Nancy) ${ }^{1}$
}

Scenography of the skin: on the body-scene as idle space (J-L. Nancy)

Diego Pérez ${ }^{2}$

UNIVERSIDAD DE CHILE

Resumen. Este artículo tiene como objetivo revisar la noción tanto de cuerpo como de piel en el pensamiento de Jean-Luc Nancy. Los alcances y discusiones de las concepciones estéticas del pensamiento de Nancy proponen una reflexión ex-criptiva del cuerpo como dispositivo central de las artes escénicas contemporáneas. Las conformaciones del ser -en contraposición a lo pensado por Heidegger-, permiten exponer, o bien, abrir el sentido del cuerpo en relación con el ser, que, en definitiva, vendría a ser la pura exposición del ser mismo como cuerpo. El cuerpo, a partir de la reflexión de su exposición, no es más que la extensión del alma incapturable, es su expeausition. De manera que, estas singularidades reflexivas sobre el cuerpo proporcionadas por Nancy permiten vislumbrar una irreductibilidad del cuerpo como extensión operativa de las artes (escénicas), es decir, un cuerpo ocioso, un cuerpo auto-encorvado en su alteración infinita. Las artes escénicas son las artes de la sobre-exposición.

Palabras claves. Cuerpo-Escena; Ocio; Expeausition; Artes Escénicas, Filosofía.

\begin{abstract}
The following article aims to review the notion of both body and skin in Jean-Luc Nancy's thinking. The scope and discussions of the aesthetic conceptions of Nancy's thought propose an exexplanatory reflection of the body as the central device of contemporary performing arts. The conformations of 'being' -in contrast to what Heidegger thought-, allow 'exposing', or, opening the sense of the body in relation to 'being', which, in short, would become the pure exposition of being same as body. The body, from the reflection of its exposition, is only the extension of the uncapturable soul, it is its expeau. So, these reflective singularities on the body provided by Nancy, allow glimpses of an irreducibility of the body as an operative extension of the (performing) arts, that is, an idle body, a self-bent body in its infinite alteration. The performing arts are the arts of over-exposure.
\end{abstract}

Key words. Body-Scene; Leisure; Expeausition; Performing Arts; Philosophy.

\footnotetext{
${ }^{1}$ Investigación financiada en el marco de la Beca Doctorado Nacional Agencia Nacional de Investigación y Desarrollo Chile ANID.

${ }^{2}$ Licenciado en Historia, Universidad Academia Humanismo Cristiano. Magister en Estudios Culturales, Universidad de Chile. Doctor en Filosofía, estética y teoría del arte. Universidad de Chile. Mail: p.perezpezoa@gmail.com.
} 


\section{Preámbulo: ob-scena}

¿Cómo se llega al mundo?, ¿cuán lejos se encuentra el mundo de mí?, ¿cuál es el espacio del ocio?, ¿cuál es su lugar? Estas son preguntas que poseen un profundo acento heideggeriano; pues, la objetivación del espacio - la espacialidad a la que remite el espacio mundo- será el gran tema no saldado por Heidegger. Así, reflexiones posteriores se encargarán del tratamiento de esta no persistencia por el lugar ${ }^{3}$. Si seguimos el parágrafo $\$ 23$ de Ser y Tiempo, podemos advertir, en una primera instancia, el tipo de constitución que se expone dentro del texto heideggeriano, de la exposición del mundo del Da-sein:

Si atribuimos espacialidad al Dasein, evidentemente ese 'ser en el espacio’ deberá comprenderse a partir del modo de ser de este ente. La espacialidad del Dasein -el cual por su misma esencia no es un estar-ahí- no puede significar ni un encontrarse en alguna parte dentro del 'espacio cósmico', ni un estar-a-la-mano en el lugar propio. Ambas cosas son modos de ser de los entes que comparecen dentro del mundo. En cambio, el Dasein está ‘en’ el mundo en el sentido del ocupado y familiar habérselas con el ente que comparece dentro del mundo. Y, por consiguiente, si la espacialidad le corresponde en alguna forma, será únicamente sobre la base de este estar-en. Ahora bien, la espacialidad de este último presenta los caracteres de la des-alejación [Entfernung] y la direccionalidad [Ausrichtung]. (Heidegger 192).

Como sabemos, el interés heideggeriano se concentrará, más que en la magnitud de las distancias, en los procesos de acortamiento (o, des-alejamientos) que el estar-en-el-mundo del Dasein despliega esencialmente. No sería imprudente asociar esa cercanía como algo que se encuentra -fuera de cualquier intento de concentrarlo en series de coordenadas-a la mano, al entender esta proximidad como algo-cerca-del-cuerpo. Pero, como ya conocemos la lógica reflexiva de Heidegger de la no apropiación óntico-fenoménica, sabemos que ese a la mano no se refiere a la cercanía ante la plenitud de un cuerpo, o bien, de mi cuerpo. Sino que, más bien, indica

\footnotetext{
${ }^{3}$ A través del título de unos de los parágrafos de Ser y Tiempo, Sloterdijk retoma la investigación heideggeriana de la existencia a partir de la inherente dimensión espacial que la recubre: "Sólo unos pocos intérpretes de Heidegger parecen haber entendido con claridad que bajo el sensacional título programático El ser y el tiempo se oculta también un tratado, germinalmente revolucionario, sobre el ser y el espacio. Bajo la fascinación de la heideggeriana analítica existencial del tiempo, la mayoría de las veces se ha pasado por alto que dicha analítica se cimienta en una correspondiente analítica del espacio, del mismo modo que ambas, a su vez, están fundadas en una analítica existencial sobre el movimiento" (Sloterdijk 263).
} 
una zona de comparecencia entre la (des)ocupación del Dasein con lo a la mano del mundo. El cuerpo queda secundarizado por otro tipo de acercamiento al mundo, debido a que:

En la cercanía significa: en el ámbito de lo inmediatamente a la mano en la circunspección. El acercamiento no toma como punto de referencia la 'cosa-yo' dotada de un cuerpo, sino el ocupado estar-en-el-mundo, es decir, lo que en este estar-en-el-mundo comparece inmediatamente. Por eso la espacialidad del Da-sein tampoco puede determinarse indicando el lugar en el que está presente una cosa corpórea. Es cierto que también del Dasein decimos que ocupa un lugar. Pero este 'ocupar' es fundamentalmente distinto del estar-a-la-mano en un lugar propio dentro de una zona. (Heidegger 135).

Estas reflexiones dejan en claro que, si bien el lugar del cuerpo-de-uno no es el de un volumen físico -ni metafísico-, así y todo, el movimiento existenciario del Dasein construye un espacio no-físico - o, de una física aparente de la naturaleza del mundo- para que la ontocronología que caracteriza la personificación del Dasein obtenga un desenvolvimiento óptimo para la lógica esencializadora de la reflexión heideggeriana. Por de pronto, el lugar aparentemente físico es ambiguo (pues, no es plenamente metafísico), debido a que el reconocimiento originario del Dasein que se da en la presencia es, por lo menos, de carácter escénico; esto quiere decir que, si bien el Dasein prescinde del espacio geográfico o físico -el espacio vulgar- para su desenvolvimiento, debe, a lo menos, representar una noción de espacio aparente para que de esa manera la lógica argumentativa de la existencia, ex-sistir, adquiera peso reflexivo. Creemos que la ocupación del Dasein por el cuerpo remite a la constante creación de un habitar postepistolar -más allá del lenguaje como morada del ser- que es, al mismo tiempo, capaz de crear un tipo de espaciamiento vinculado a la formación o esquematización del pensamiento meditativo y performático en torno al cuerpo antes-del-cuerpo: un corpus.

La ocupación del Dasein es radicalmente distinta del hacerse-cargo de un ente en un lugar codificado y en un tiempo serializado. Esta ocupación, en cambio, se refiere a un des-alejamiento del mundo de la ocupación, donde el Dasein, en su esencia, comienza a ocuparse de sí mismo como ente que comparece en el mundo libremente des-alejado. Esto quiere decir que la potencia del Dasein, su esencialidad posible, inicia la tarea de acercamiento al mundo alejándose, para, así, restituir un tipo de ocupación-de-uno en la forma de una des-ocupación del mundo a la mano, una libertad libre de cuerpos. Por tanto, ¿cuál sería el lugar de cada uno y cada una en el mundo? Cuando nos ocupamos-de-uno, ¿cómo exponemos nuestra presencia en el mundo?, ¿de qué trata, precisamente, esa libertad?, ¿es posible la libertad sin la forma, sin medios? Preguntas no exentas de complejidades y que Nancy intentó reflexionar y descifrar a través de la consulta sobre el cuerpo y los modos de exposición en el mundo. A continuación, resumiremos la reflexión nancyeana sobre el cuerpo y la escena -a partir de Heidegger- en tres momentos. Y así dar cuenta de cómo, en 
definitiva, el problema del cuerpo en Heidegger es aún un modo de ocupar-se ocioso y necesario para cualquiera, mediado por las distancias que se construyen siguiendo la lógica del teatro y la escena en filosofía.

Probablemente, antes de iniciar la paráfrasis en torno al cuerpo-escena llevada a cabo por Nancy, sea sugerente tratar de ofrecer un panorama abierto, o, por lo menos, elemental, en torno a la noción de cuerpo que Nancy posee. Para esto, habría que considerar algunos pasajes fundamentales de su obra Corpus -sin dudas, su reflexión más amplia realizada sobre el tema. "Hoc est enim corpus meum" es la frase que, espectralmente, acompaña toda la reflexión de Nancy -y a Occidente- sobre el cuerpo, en dicha obra. El fantasma del cuerpo, aquel fantasma heredado de Heidegger, espectros de la tecnocracia de los cuerpos, espectros del aparato-cuerpo, cuyo enfrentamiento existencial lo lleva a cabo Nancy, y se hace cargo, a su vez, de la aversión que Heidegger poseía contra la técnica. Seguramente, la lógica heideggeriana no dimensionó el impacto de la provocación sobre el cuerpo por las diferencias establecidas hacia los aparatos del mundo. Pero, Heidegger sí estuvo seguro de que, si se arriesgó a dar riendas sueltas al pensamiento existencial, fue gracias a que pudo ensayar la posibilidad práctica de que el cuerpo cosificado es capaz de experimentar la sensación temerosa del cuerpo como dispositivo disperso -si no, hubiese sido imposible, en ese caso, tener alguna aversión hacia la técnica. Debe haber algo de afecto en su lógica del cuerpo que teme ante la dispersión del mismo cuerpo. O, más precisamente, el famoso rechazo de la técnica en Heidegger es menos conocida que su rechazo al cuerpo, es decir, del cuerpo vulgar. Habría otro cuerpo en el cuerpo de Heidegger; habría un corpus, donde el pensamiento del cuerpo es más intenso que el cuerpo mismo.

Nancy comprendió cuidadosamente esta referencia paradójica; la tendencia reflexiva del cuerpo, la extensión que pretende ser el contenedor, el cuerpo propio, de la imaginación subjetiva, de los pensamientos del cuerpo, no son más que constantes dispersiones de eso que se desea reunir. La abstracción del pensamiento ante el cuerpo es, aquí, nefasta. De este modo, el cuerpo es un invento occidental que responde a una obsesión milenaria sobre nuestras cercanías con el mundo, pero, al mismo tiempo, es la pretensión de la subjetividad que desea distinguirse del mundo. Así, el cuerpo es el límite de lo más cercano de uno y lo más extraño, a la vez. Ahora bien, si el cuerpo es un invento, ¿qué queda de su naturaleza, de su desnudez? Precisamente, esa sería la función diseñadora de su reunión: activar un límite de eso-mío que refleja el anudamiento constante de eso imposible de desnudar. El cuerpo, por tanto, se sostiene de un eje gravitacional estético que hace eco de la organicidad del cuerpo propio; pues, propio es el corpus que sostiene el insostenible deseo para que ese cuerpo sea de nosotros. Fuerza del pensamiento cuyo peso es del cuerpo. El cuerpo fuerza al pensamiento al movimiento, a la actividad propia del pensamiento. De ese modo, lo único que pensaría el pensamiento es el cuerpo; mejor dicho, el pensamiento desea al cuerpo como forma de algo posible. Esa inclinación, esa fuerza, hace que el cuerpo escriba su propio pensamiento; hace, sin más, que el cuerpo se escriba a sí mismo.

El cuerpo es flotante, pero el corpus debe tocar tierra -es siempre lo que hace falta. Que el cuerpo se escriba no hace referencia al cuerpo como objeto de la escritura. Las imágenes, los signos, el semiocapitalismo quedan fuera y el cuerpo (se) escribe, él mismo, con la fuerza de su desnudez, tal como el cuerpo es en las fronteras de sus vínculos con la multitud flotante. Por tanto, no se trata de entregar o implementar significados al cuerpo -ya que, el cuerpo no se es-cribe ni inscribe, sino que se inscribe hacia afuera, excretando su significado. A esto Nancy lo llama excripción, o sea, "su puesta fuera de texto como aquel movimiento más propio de su texto: el texto mismo abandonado, dejado sobre su límite" (Nancy 13). El cuerpo es arrojado hacia el límite, al borde, hacia la exposición de una constante significación abismante de sus tocares. El pensamiento toma el rumbo de las delimitaciones dibujadas por el cuerpo, de este abismo, en vez de concentrarse en 
una falsa dispersión. El cuerpo, de esta manera, recoge los ejercicios del pensamiento; las fuerzas, intenciones, y contemplaciones del pensamiento son arrojadas al cuerpo. Así, el cuerpo es un espacio abierto, un espacio espacioso; es el lugar del pensamiento. El cuerpo cumple los deseos del pensamiento por querer-existir. Pues, "el cuerpo-lugar no es ni lleno, ni vacío, no tiene ni fuera, ni dentro, como tampoco tiene partes, totalidad, funciones, o finalidad" (Nancy 13)., lo que hace del cuerpo un simple, pero potente, límite de la existencia. ¿Cómo identificamos los límites del cuerpo, lo que recubre al cuerpo, lo que permite el sentido de su excripción?

La única zona posible de in-scripción es el pliegue de la piel; permite que el cuerpo se exponga sin esencia. La existencia es la piel. La existencia es exponer-se. El cuerpo da lugar a la existencia. Piel tensa, piel retraída; existencia tensa, in-tensa, existencia recuperada, re-traída. Movimiento de contracción y dilatación, movimiento de la existencia sin esencia: "el cuerpo no es ni substancia, ni fenómeno, ni carne, ni significación. Sólo el ser-excrito" (Nancy 19). De ahí que el cuerpo no pueda escribirse, sin más, solo ser-excrito. El cuerpo es lo que no se puede escribir, límite de la letra, de la filosofía que se escribe. El cuerpo es inútil a la escritura, no se emplea a nada. Es inoperante a la comunidad literaria. "Quizás cuerpo es la palabra sin empleo por antonomasia. Quizás es, de todo lenguaje, la palabra de más” (Nancy 19). Sobra y suplemento del pensamiento, la piel comienza a operar como existencia de un cuerpo que desea ex-ponerse, cuerpo ocioso e inoperante. Ahora fracturado por esta punta que es el cuerpo-expuesto. La piel, en tanto, no es lo epidérmico que recubre un cuerpo; es, mejor dicho, lo que recubre la existencia sin esencia. Por este motivo es que el cuerpo de Nancy, su corpus, sea siempre pura exposición. Exposición de la piel, expeausition de la existencia. No hay un en-sí del cuerpo, lo que hay es un en-sí exponiéndose a cada instante. Es decir, expielación; exposición de una piel que extraña el cuerpo para convertir al cuerpo en ser-tal, o sea, otro cuerpo, posibilidad de otro cuerpo, ocasión de su estiramiento, de su ex-tensión, de su ex-posición.

La expielación no es la exposición o la puesta-en-escena de la intimidad de un cuerpo. No hay representación de una intimidad o un secreto. Hay, más bien, ex-timidad; es decir, exposición de la intimidad misma. Los sus adentros no son traducidos ni representados, son expuestos infinitamente en el espacioso encuentro entre sí con el sí mismo del cuerpo. El cuerpo no necesita el paso de un momento a otro, es el momento mismo de su dislocación: "el cuerpo es sí mismo en la partida, en cuanto que él parte, en cuanto que justo aquí se separa de aqui'" (Nancy 29). Instante de devoción del cuerpo mismo, de auto-devoción, o, mejor dicho, momento de autoposición. De modo que, "expuesto, por tanto: pero no es la puesta ante la vista de lo que primero estuvo oculto, encerrado. Aquí, la exposición es el ser mismo. O todavía mejor: si el ser, en cuanto sujeto, tiene por esencia la autoposición, aquí la autoposición es ella misma, en tanto que tal, por esencia y por estructura, la exposición. Auto=ex=cuerpo. El cuerpo es el ser-expuesto del ser" (Nancy 29). En conclusión, corpus es lo que siempre falta. La noción de cuerpo de Nancy -como para hablar de cuerpo-escena- no sería ese cuerpo que se coloca a la vista. Es, más bien, un cuerpo que se desnuda re-iterativamente. Una promesa, promesa de cuerpo. Cuerpo es colección de cuerpos ${ }^{4}$.

\footnotetext{
4 “Corpus: un cuerpo es una colección de piezas, de pedazos, de miembros, de zonas, de estados, de funciones. Cabezas, manos y cartílagos, quemaduras, suavidades, chorros, sueños, digestión, horripilación, excitación, respirar, digerir, reproducirse, recuperarse, saliva, sinovia, torsiones, calambre y lunares. Es una colección de colecciones, corpus corpurum, cuya unidad sigue siendo una pregunta para ella misma, Aun a título de cuerpo sin órganos, éste tiene al menos cien órganos, cada uno de los cuales tira para sí y desorganiza el todo que ya no consigue totalizarse" (Nancy 23)
} 


\section{Momentum: quo corpus (I)}

Entonces, hablábamos de tres momentos, de tres movimientos a propósito del cuerpo: el primero es aquel que identifica la relación del cuerpo con el existir (punto que se relaciona, directamente, con la reflexión anterior). El segundo tiene que ver con la vinculación entre cuerpo y teatro (quizás, la relación más polémica de las comprensiones sobre cuerpo y sus representaciones), la reflexión de un cuerpo-escena mediante su constitución dramática. Por último, encontramos un tercer momento, donde el cuerpo encuentra la escena -skenè- que cobija sus aproximaciones y configuraciones, aproximaciones y separaciones de los cuerpos como generadores de sentido completamente materializado. Estos tres momentos pretenden crear una línea tentativa del ocio como tiempo-de-uno-en-el-cuerpo. La fisionomía del ocio es siempre la de un cuerpo que se ocupa de sí mismo, en su constante ex-posición, como cuerpo que se toma su tiempo junto a otro.

Ya poseemos una mínima aproximación a lo que se puede llamar existencia, es decir, aquello que Heidegger ya entendía por estar-ahí [Vorhandenheit], pues, "la esencia del Dasein consiste en su existencia [...] en este ente no son, por consiguiente, 'propiedades' que estén-ahí de un ente que está-ahí con tal o cual aspecto, sino siempre maneras de ser posibles para él, y solo eso" (Heidegger 69). La analítica de la existencia del Dasein es siempre un tipo de existencia que conlleva la activa participación de la esencia del Dasein -como cercanía al cada vez que soy yo mismo-, desplazando, de este modo, la jerarquía histórica que poseía la ontología existencial en torno al ser (subjectum) de los entes en la memoria filosófica. La reconocida diferencia ontológica era establecida, en tanto, a través de lo que el mismo Heidegger denominaba como hilo conductor ontológico. No obstante,

La evidencia óntica de la afirmación de que soy yo el que cada vez es el Dasein no debe inducir a pensar que con ello queda inequívocamente trazado el camino de una interpretación ontológica de lo así "dado". Es incluso cuestionable que el contenido óntico de aquella afirmación interprete en forma adecuada lo fenoménicamente dado el existir [Dasein] cotidiano. Bien podría ser que el quién del existir cotidiano no fuese precisamente yo mismo (Heidegger 142).

Sabemos que este parágrafo abre el debate de las problemáticas postmetafísicas de la identidad moderna, o bien, viene a plegarse a la serie de intervenciones que -por ejemplo- el psicoanálisis, y posteriormente las empresas deconstructivas, realizarán sobre los modos de ser de la época moderna. In-der-welt-sein, ahí, siempre dado en la forma sustraída, en la elipsis de la naturaleza, será estar dentro y no en la platea. Ahora bien, lo señalado anteriormente también abre una arista que el propio Nancy se atrevió a reconducir: representar la existencia antes o detrás del existir más allá de lo dado -ob-ceno. El cuerpo -como veníamos diciendo- posibilitará la existencia, cuestión que Heidegger no quiso referenciar producto, seguramente, de toda la lógica reflexiva que había montado o construido a partir de su personaje filosófico: Dasein -"quizás al referirse a sí mismo en forma inmediata el Dasein diga siempre: 'este soy yo', y lo diga en definitiva 
más fuerte que nunca cuando 'no' lo es" (Heidegger 142). La afirmación de un cuerpo -junto a la aceptación o negación de los signos que lo recorren- es parte esencial de la actividad ociosa. Es parte importante, al mismo tiempo, del existir. Para a-firmar un cuerpo debemos concentrarnos en el corpus que lo hace posible. Y es en este punto donde el objetivo se vuelve, por decirlo de alguna manera, irrepresentable. Es, precisamente, ese punto, justo ahí detrás, de mi cabeza, mi cráneo, el punto ciego del corpus. A partir de Heidegger existir se trata de estar-dentro-en-el-mundo, no delante; un poco más acá, y no más allá. Consultamos -junto a Nancy- por el en heideggeriano; ese espacio del dentro cuyo mundo es un despliegue y nunca un espacio geográfico, una ontotopología. ¿Qué o quién se despliega? Una pregunta perteneciente a la habladuría, y no al auténtico preguntar del Dasein. El límite del Dasein en su propia representación. Para que ese dentro tenga sentido, debe haber algún sujeto; algo donde sujetar ese mundo. Una vez arrojado el nuevo mundo moderno, el ser comienza la búsqueda incesante de la originalidad del Dasein como existencia. Pero, como sabemos, esta existencia busca "disociar tan profundamente como sea posible el orden del existir de los órdenes del conocer, del representar, del figurar y también del medir y evaluar" (Nancy 317). Sin embargo, ¿con qué materiales se construye la escena-da-sein?, ¿cuál es el territorio con el que el Dasein se hace de su existencia? Evidentemente, en el existir del Dasein hay un deseo por existir; la existentia desea existir, "eso forma parte de su proyecto, de la proyección de su ser-arrojado. Forma parte de su ser en el mundo" (Nancy 317). Ese deseo ha tenido varios nombres: voluntad, pulsión, potencia, etc. Heidegger prefería la actitud del director teatral, un poco más reprimida, pues, prefería estar tras bambalina, fuera-de-escena, observando la materialización de su obra y trazando el guion de camino al habla. Nancy, por su parte, se hace cargo de esta despreocupación de Heidegger por la puesta-en-escena de la existencia material.

La puesta en escena de la existencia es intensificación de la presencia. Este asunto desplaza indefinidamente la preponderancia de las materialidades escenográficas que, más que producir la presencia, decoran la llegada de una presencia. Podríamos decir, a partir de esta secundarización de los materiales escenográficos tradicionales de la puesta en escena, que la materialidad escenográfica se traslada, cambia de foco, ahora concentrada en la piel de la presencia. Esa piel es el cuerpo, expielación (expeau); piel que servirá de representación o figuración de aquello que desea presentarse. La contradicción cae a la vista, ¿cuál es la piel heideggeriana con la que se recubre la existencia de su corpus -su texto, su obra?, ¿qué hacemos con la (in)materialidad heideggeriana? Estas preguntas apuntan en resolver lo siguiente: "no hay siempre sino el uno y, por lo demás, ése es también el motivo por el que la cuestión del otro se plantea de manera tan compleja como cuando nos preguntamos cómo un sujeto puede reconocer a otro sujeto, cómo el ego se refiere al alter ego" (Nancy 320). Es casi inevitable pensar -ya lo dice Nancy- que esa comparecencia con otro se da generalmente dentro de la lógica del Uno. El ser-con se reduce a un tipo de puesta en común que, tendencialmente, no puede evitar la sintetización de la ipseidad del Uno, uno al lado de uno. Por lo tanto, el orden de la existencia solo se da en una dimensión de lo espacial. El cuerpo, pero por sobretodo la piel, se manifiestan como condición de posibilidad de la presencia. El cuerpo es el nuevo teatro. Con Artaud, tal vez, ya lo reconocíamos. Sin dudas que las artes escénicas, en general, han pensado, también, mucho mejor las formas de ser de los individuos en el mundo. Pero, los conflictos entre filosofía y teatro aún se encuentran, dramáticamente, en gestación. El espacio desarrolla no solo la ubicación del peso discursivo de la filosofía, sino que, a la vez, habilita las posibilidades de su trans-formación, es decir, las formas trans de su ejercitación. Cuando la filosofía toma cuerpo, el ocio también lo hace.

De modo que este primer momento resume lo que comentábamos inicialmente en esta sección: las condiciones de posibilidad esquemáticas que hacen posible lo posible, abandonan la temporalidad trascendental y se filtran en el espacio rugoso del cuerpo-cualquiera. La piel que 
permite la puesta en escena del peso del pensamiento, la piel que soporta las formas incorpóreas del pensar se torna como la forma expositiva desarrollada en el ámbito contingente de cualquiera. Una piel, claro está, que no se puede reducir a lo epidérmico, sino que, ahora tendría que comprenderse como una expielación; cuando el poro de la piel se abre hasta cerrarse en su respiro, cuando la piel se expone entre un cuerpo y otro, cuando cualquiera toca a cualquiera (Derrida 78).

\section{Momentum: nunc theatre (II)}

Un segundo momento, en Nancy, reconoce que la reflexión llevada a cabo sobre el cuerpo y la existencia entra en terreno teatral y de las artes escénicas. Así, no con tanta precaución -pues, ya no es necesaria-, Nancy inicia su comentario sobre el cuerpo-escena a partir de la distancia, del espacio expandido, entre un cuerpo y otro, pensada históricamente por el teatro y la danza. El teatro es un arte que se funda en una distancia originaria: es el arte de la distancia de los cuerpos, del espectador y del actor. La danza, por su parte, hace proliferar otra distancia: la distancia del cuerpo sobre sí mismo. A partir de las reflexiones planteadas por Artaud, a propósito de la creación y el cosmos, Nancy se aventura en una reflexión mucho mayor: "planteo solamente, de acuerdo con él, que hay una opacidad, un espesor material indispensable en la presentación de lo que está en juego en la creación o en el cosmos - como creación y como cosmos- en la medida en que el conflicto pertenece a aquello que está en juego. El conflicto cósmico (metafísico, dice en otra parte) requiere ser presentado como drama” (Nancy 323). La materialidad de ese espaciamiento busca ser expuesto incesantemente. El vacío entre los cuerpos no tendría porqué adquirir una apreciación negativa, nihilista. Ya lo dejaban claro en Oriente, pues "la nada hacia el despertar de la conciencia humana, el ver el ser mismo directamente como la nada es tanto el punto en el que el 'yo' puede intuirse a sí mismo directamente, como el punto en el que el absoluto llega a ser más plenamente real" (Heisig 77). Valoración oriental del cuerpo que no dice nada. Escena de la distancia entre los cuerpos y del cuerpo mismo. Para Nancy, por su parte, el cuerpo es el desencadenamiento de un conflicto cosmológico; una exposición dramática que comienza a ejercer su trayectoria protoexistencial mediante la exposición esencializante del cuerpo (in)comunicante. De manera que, lo que trata de señalarnos Nancy es que el material de las artes escénicas se encuentra ya de antemano dado en la realidad. Esto quiere decir que el cuerpo no necesita ser-hablado, pues, el cuerpo habla dramáticamente en las acciones mundanas; el cuerpo no necesita ser movido, desplazado, pues, el cuerpo danza y se mueve cotidianamente. Entre un cuerpo y otro comienza a tejerse la historia del teatro y de la filosofía: si el cuerpo habla de antemano, entonces, lo que hace el teatro es reposicionar la coro-grafía de los cuerpos esencialmente hablantes; si el cuerpo se mueve y grita al nacer, entonces la danza reposiciona los cuerpos diagramando los gestos intrauterinos. Esto es fundamentalmente reparto de sentido. El cuerpo como ex-pielación es el cuerpo abriéndose a sí mismo, o sea, generación de sentido por contracción y distensión. El cuerpo habla y moviliza, en ese caso, no porque ejecute algún modo de enunciación previsible. Probablemente sea complejo identificar ese aspecto. Más bien, tiene que ver con la capacidad que la piel ex-pone su locución y su red sensorial de intercomunicación gestuales y perceptivas. Así;

Las otras partes del cuerpo', como dice Proust, no dejan de ofrecer también a su vez

aproximaciones al alma. Mis manos, mis piernas, mi cuello, mis posturas, mis

trazas, mis gestos, las caras que pongo o los aspectos que tengo, el timbre de mi voz, 
todo lo que podríamos llamar la pragmática del cuerpo, todo sin duda, todo sin excepción en toda la superficie de mi piel y con todo aquello con lo que puedo cubrirla y ornarla, todo expone, anuncia, declara, dirige algo: unas maneras de aproximarse o de separarse, unas fuerzas de atracción o de repulsión, tensiones para agarrar o soltar, para tragar o para expulsar. (Nancy 326).

Este vacío entre un cuerpo y otro comienza a llenarse de sentido. Y los cuerpos involucrados comienzan a experimentar esta producción de sentido como una constante contracción y dilatación de las maneras de captación de ese sentido a nivel subjetivo: es la forma de un drama del cuerpo como construcción de una escena puramente corporal de contracción del sentido. Es un drama del sentido del cuerpo cuya fuente no es una experiencia subjetiva del dramatis personae, sino el drama de un cuerpo que no desea desalojar su contracción de sentido con los demás cuerpos. Pura afectación como sentido del sentido. De esta manera, la juntura de los cuerpos invita a pensar los cuerpos que faltan. Esto no indica la serie constitutivas de cuerpos-unidades que faltan -no es la cifra del cuerpo, ni sus singularidades, las ausentes. Sino que aquel cuerpo-otro que siempre invita a alejarme de los demás cuerpos, en plena reunión o co-locación de los mismos en busca de sentido. El sentido, en tanto, es el impulso del cuerpo hacia ese vacío del cuerpo-otro que falta, pero que se encuentra junto-a-mí, casi a mi-lado.

\section{Momentum: corpus adhuc (III)}

De aquí se desprende el tercer momento de la reflexión sobre el cuerpo-escena: el cuerpo como una escena que cobija las inmaterializaciones del sentido-compartido. La escena-como presentación de los cuerpos- es un espaciamiento de sentido, de envíos y renvíos de la relación expuesta de los cuerpos. Por tanto, la reunión de los cuerpos no es la ocupación de un lugar o de un tiempo en manos de un conjunto de unidades corporales masificados o serializados. La reunión de los cuerpos es siempre la de un cuerpo-otro consigo mismo; una reunión que es, más bien, la falta de sentido sustancial, trascendental y existencial, en búsqueda de un sentido corporal erizante de la piel -o sea, sentido mismo. La escena, por tanto, es "un lugar donde se engendra y se toma el tiempo propio de una presentación (de cuerpos: este complemento podría ser elidido) en cuanto impulsos de sentido entre los vacíos de sus existencias fortuitas, un lugar donde lo fortuito mismo adquiere necesidad de drama y donde el vacío adquiere consistencia de compilación del sentido: todo eso es lo que llamamos una escena" (Nancy 327). Esta noción de escena nos ayuda a comprender más claramente la bifurcación que desea realizar Nancy sobre el significado del cuerpo: el sujeto es pretensión de sentido, mientras que el cuerpo es sentido en acto. De este modo, la escena deja de ser una representación de una idea (la puesta-en-escena de un pensamiento singular), y pasa a constituirse, mediante la performatividad de los cuerpos relacionados -sexual, intelectual o trágicamente-, en la escena de la materialidad del ser-con-junto-a.

Tal como veíamos inicialmente en esta investigación, la escena -la skenè- adquiere sus formaciones etimológicas de aquel dispositivo provisorio abrigador, cuya funcionalidad es cobijar a los individuos en una intimidad pasajera frente a las adaptaciones geográficas. Sin embargo, no es solo una protección espacial, es, a la vez, una cobija temporal; la escena se abre y se cierra a sí 
misma, ya que es un espacio-tiempo ocioso que se ocupa del sentido como espaciamiento entre los cuerpos. "Tiempo que no es de sucesión sino de paso, breve dilatación de un instante retirado en el curso del tiempo" (Nancy 330). La escena como paso del tiempo. El ocio como instante artificial entre cuerpos expuestos. El sentido es formación de ese paso del tiempo; pues, el entrelazamiento provisorio de los cuerpos expone sentido escenográfico, trozos de tiempo sustraídos del devenir del tiempo. No puede haber sentido sino entre cuerpos, pasando de uno al otro. La escena, en tanto, es saturación de sentido, de re-presentación, donde se re-itera la presencia. Y como tal, el cuerpo es ya presentación donde la representación teatral es reposicionamiento de los cuerpos ya siempre presentados; el cuerpo es ya movimiento donde la coreografía de la danza es reconducción de los gestos y el baile de los cuerpos ya siempre movidos. Es por este motivo que la presentación de los cuerpos, su escena, antecede toda gramática de la presencia: precede a la existencia misma, no solo a su percepción corporal, sino, también, a la substanciación de la existencia. El cuerpo permite la existencia como exposición de la existencia misma; el cuerpo es el ser de la existencia.

Todo se trata de teatrocracia: es decir,

Nada menos que el 'mundo como teatro' tal como cabalmente lo conocemos desde Calderón y Shakespeare, pero también tal como de hecho toda nuestra tradición desde la caverna de Platón al menos- ha reflexionado sobre ello hasta la extenuación, ese 'mundo como teatro' en cuanto verdad, en la medida en que y porque el cuerpo se revela verdad del alma: verdad que se empuja ella misma a escena o más precisamente verdad que monta una escena (Nancy 333).

La escenografía de la piel es la obsesión de la realidad en la práctica de la filosofía occidental. La comparecencia de los cuerpos se convierte en la escena donde el sentido se edifica como sentido portátil del entre los cuerpos expuestos, llegando a concebir las frustraciones anímicas como anécdotas minimizadas de las formas de vidas contemporáneas. La cultura, de esa manera, se encarga de someter a los cuerpos al espectáculo-estrés de las miradas y las recreaciones ambientales psicoauditivas del mercado cultural: grandes conciertos de música, estadios repletos de cuerpos exaltados, buses aéreos llenos de personas, etc., la compilación de cuerpos garantiza el ciframiento mercantil del mismo. A la cultura -o bien, al culto- ya lo antecede esa exposición de los cuerpos dis-puestos de sentido, donde la verdad se asoma como deseo por concretar la lógica de un sentido perceptivo y cautivador. El culto contiene esa teatralidad necesaria para que la expectativa se transforme en el centro de captación del sentido. De la misma manera, la filosofía habita las formas culturales: el rito y el teatro del saber como danza de la lengua. La filosofía, en la forma repetitiva, poco a poco debe ir abandonando los conatos que la arrastran hacia esa ritualidad del culto al pensamiento y sus figuraciones como concentración de cuerpos puramente pensantes, para abrir el pensamiento al cuerpo cualquiera. Intrigas sobre el Ser, dramas sobre la verdad: la apertura debe correr por parte de los cuerpos expuestos cuya piel telecomunica la necesidad ociosa de ocupar un cuerpo-otro. El sentido toca los cuerpos incorporalmente. 
El ocio, en tanto, se convierte en un tipo de inmanencia del sentido del cuerpo bastante singular: es la piel del pensamiento, ni trascendencia ni inmanencia absoluta, sino que siempre espaciamiento temporal. Y la filosofía, por su parte, es aquella teatralidad que se construye a partir de su doble: pensamiento del cuerpo, cuerpo-pensante-cualquiera, cuerpo-ignorante. El ocio es escena (skenè) -pues, abriga a los cuerpos-cualquiera expuestos en el tiempo mediante un tiempo alternativo o artificial, adelantándose (esceno[historio]grafía) a la posible re-presentación del tiempo. Cuerpos ya no de la ignorancia, sino de la lejanía y la distancia de un saber del cuerpo otro. En ese caso, escena como inmunología histórica, escena como asilo temporal ante la catástrofe; recorte de tiempo en el tiempo, ornato y cobertura ante el paso del tiempo -escena como momento. El ocio acerca al cuerpo a la realidad como escena de un cuerpo-otro, extraño. Por otra parte, la filosofía es entendida como dúplice, o sea, re-dobla el cuerpo bajo la inconmensurabilidad del lenguaje distanciador. El teatro filosófico se construye gracias a los parámetros extremos de la realidad material que los constituye. Por lo mismo, su escenografía es construida por cuerpos expuestos a un tipo de agotamiento que consiste en redundar la energía del alma. Las filosofías postmetafísicas comprendieron la importancia del cuerpo a partir de que advirtieron que el cuerpo es el dispositivo estético que permite un vínculo más cercano con el alma, como si el cuerpo individual no estuviese montado sobre terrenos metafísicos y protocristianos que aún lo sostienen.

Es necesario comprender que ocuparse-de-uno en el cuerpo es abrir la lógica individual y pseudopropietaria del cuerpo mercantil hacia un festival ocioso del ser-con-cualquiera. Cuando el cuerpo es ocupado-por-uno se distorsionan las lógicas del capital y el trabajo que lo soportan. Capital es cuerpo-cifrado, cuerpo-plusvalía, cuerpo-semio-significado. La intercambiabilidad del cuerpo debe construir otras lógicas de intercomunicación a las cuales -por su esencia expositivatiene que someterse. El ocio es el tipo de escena que no sobreexpone la esencia expositiva de los cuerpos, ni siquiera a la clase y el esfuerzo, y la lucha de clase . Más bien, protege la piel de los cuerpos que tienden a ser capturados por las lógicas que usufructúan, violentamente, con los nuevos contornos de la figura deseante expulsora de sentido (identidad). La paciencia de Nancy -por ejemplo- para pensar el cuerpo (su cuerpo mismo), se produjo creando esta habitabilidad ociosa del contacto telemático del cuerpo ex-crito, del sentir extraño del cuerpo, de la comparecencia infinita de los cuerpos extraños, corpus, al fin y al cabo, ya que, "lo queramos o no, los cuerpos se tocan en esta página, o bien ella misma es el punto de contacto (de mi mano que escribe [que teclea, en mi caso], de las vuestras que sostienen el libro [libro digital sostenido por la mirada, en mi caso]) [...] Al final, vuestra mirada toca los mismos trazos de caracteres que ahora toca la mía, y vosotros me leéis, y yo os escribo" (Nancy 42). Por tanto, es válido preguntarnos: ¿cómo el cuerpo habla por fuera-del-lenguaje productivo? ¿Cuál es la dirección de los cuerpos expuestos y liberados? ¿Cuál es el lugar que habitarán estos cuerpos no-cifrados? ¿Poseen alguna intención, alguna orientación? ¿Se dirigen hacia alguna realidad? Y bueno, por lo demás, al mundo se llega danzando, antes que nada.

\section{Conclusión: ad corpus}

Preguntas: ¿hacia dónde va el cuerpo? Cuando (se) mueve, ¿qué desea escapar? Si el ocio es el tiempo-de-uno, ¿cuál es el cuerpo del tiempo?, ¿cómo toma cuerpo el tiempo-de-uno? El cuerpo ocioso es el cuerpo improductivo, cuerpo irreductible; cuerpo lleno de cuerpos, cuerpo des-atado de las lógicas del actuar productivo - productivo en las artes, en el trabajo, en la sexualidad, en la escritura. ¿Qué cuerpo queda, resta, cuando el cuerpo deja de ser, dejando el cuerpo?, ¿a dónde va el cuerpo que resta? Si el alma es extensión del cuerpo, ¿qué cuerpo sobra, o queda, en el rebrote extendido? 
Las artes escénicas son las artes de la sobre-exposición, es decir, colocan en escena el cuerpo ready-made, siempre extendido, siempre escenificándose; momento de la extensión, momento del cuerpo ya nacido, que actúa danzando, que danza actuando. Todo pensamiento es escenografía de una pasión y toda reunión es coreografía de una ilusión. En definitiva, las artes de la escena son las artes de la piel, de la expielación, del abandono del cuerpo propio; coreografía epidérmica del alma, escenografía y dramaturgia de lo erizante. Puesta en escena de la carne. Eterna exposición de la membrana sensitiva. Prolongación de lo articulable, lo ensamblable, lo plegable. Piel del pensamiento compartido, reunido, abigarrado. Las artes de la escena crean corpus restante de los cuerpos restantes, cuerpos ociosos, radicales, experimentales, políticos, disidentes. Todo cuerpo va hacia otro cuerpo; no hacia otro con-tacto, hacia otro sujeto-cuerpo. Más bien, hacia un cuerpo ficcionado. Las artes de la escena son las artes de la ficcionalización del cuerpo, del pensamiento del cuerpo. O, mejor dicho, todo pensamiento del cuerpo es ficcionalización en sí mismo. Todo arte debe liberar al cuerpo, des-coreografiar, des-dramatizar. Espera del cuerpo que viene. 


\section{Bibliografía}

Derrida, Jacques. El tocar, Jean-Luc Nancy. Trad. Irene Agoff. Buenos Aires: Amorrortu, 2011. Impreso.

Heidegger, Martin. Ser y Tiempo. Trad. Jorge Eduardo Rivera. Santiago, Chile: Universitaria, 2015. Impreso.

Heisig, James. Filósofos de la nada. Un ensayo sobre la Escuela de Kioto.Barcelona: Herder, 2002. Impreso.

Nancy, Jean-Luc. Corpus. Trad. Patricio Bulnes. Madrid: Arena Libros, 2003. Impreso.

---. 58 indicios sobre el cuerpo. Extensión del alma. Trad. Daniel Alvaro. Buenos Aires: La Cebra, 2011.Impreso.

---. La partición de las artes. Valencia: Pre-Textos-Universidad Politécnica de Valencia, 2012. Impreso.

--- \& Monnier, Mathilde. Allitérations Conversations sur la danse. Paris: Galillé, 2005. Impreso. Quignard, Pascal. El origen de la danza. Trad. Silvio Mattoni. Buenos Aires: Interzona Editorial, 2018.. Impreso.

Sloterdijk, Peter. Sin salvación. Tras las huellas de Heidegger. Madrid: Akal, 2011. Impreso.

Recibido: 12 de Junio de 2020 Aceptado: 21 de Diciembre de 2020 